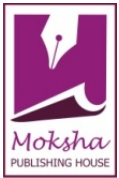

Research Article

www.ijrap.net

\title{
CLINICAL EVALUATION OF COLICARMIN PLUS DROPS ON COLIC, GRIPING PAIN, INDIGESTION, AND FLATULENCE IN PEDIATRICS PATIENTS \\ Patel Kirtikumar ${ }^{1}$, Gathani Rupali ${ }^{2}$, Mishra Devendra ${ }^{3 *}$ \\ ${ }^{1}$ Physician, Radhika Maternity home, Kalawad road, Rajkot, Gujarat, India \\ ${ }^{2}$ Regulatory Affairs Officer, Ban labs (P) Ltd., Rajkot, Gujarat, India \\ ${ }^{3}$ Product Executive, Ban labs (P) Ltd., Rajkot, Gujarat, India
}

Received on: 25/05/16 Revised on: 14/06/16 Accepted on: 29/06/16

\author{
*Corresponding author \\ E-mail: productmanagement@banlab.com
}

DOI: $10.7897 / 2277-4343.074144$

\begin{abstract}
This was an open label, non-randomized and non-comparative study to assess effect of Colicarmin plus drops on Colic, Griping Pain, Indigestion, Flatulence, and diarrhea in Paediatrics patients. A total 75 patients were enrolled in study, all the patients were followed-up at the end of treatment and clinical examination was done, along with recording of adverse events. Infants below 6 months: 1-4 drops, 4-6 times a day, 6 months to 1 year: 45 drops, 4-6 times a day, 1 year to 3 years: 5-6 drops, 4-6 times a day, 3 years to 5 years: 6-10 drops, 4-6 times a day. Colic and griping pain: More than 50\% patients got relief in five minutes, Indigestion: More than 50\% patients were cured in 24 hours, Flatulence: More than $50 \%$ got relief in just 15 minutes, Diarrhea during teeth eruption: More than 50\% patients got relief in 4 days. Colicarmin plus drops an Ayurvedic formulation has benefits like digestive, carminative and spamolytic which gives relief from colic and griping pain, indigestion, flatulence, nausea and diarrhea without any side effects.
\end{abstract}

Key Words: Digestive, Carminative, Spasmolytic

\section{INTRODUCTION}

Evaluation of Abdominal pain can challenge both parents and the pediatrician. Possible causes for a child's abdominal pain range from trivial to life- threatening, with little difference in the child's complaints ${ }^{1}$. The only symptom which they show is crying every now and then on account of abdominal discomfort occurring due to flatulence, indigestion, nausea, vomiting or colic. Colic is a common childhood condition marked by prolonged episodes of intense crying, in almost $10-30 \%$ of newborn babies usually during the evening hours ${ }^{2}$. Some other problems commonly occurring with babies are diarrhea i.e. increased frequency and water content of stools, gas, indigestion which is associated with chronic relapsing gastrointestinal problem. It is important to distinguish colic from specific disorders that can produce abdominal pain or cramping and prolonged crying, including infection, food allergies, or intestinal obstruction. If no physical causes can be found, colic is usually the diagnosis ${ }^{3}$. Some of the possible causes of colic are abdominal discomfort and intestinal gas (e.g., caused by abnormally rapid digestion [hyper peristalsis], or high levels of intestinal hormones, such as mottling), Allergy or intolerance to breast milk, hunger or overfeeding, immature digestive system or central nervous system, oversensitivity to stimulation (e.g., activity, excitement, anxiety) etc.

Some of the herbs have tendency to cure infantile abdominal problems some of which are listed in (Table 1). ${ }^{4-5}$

\section{MATERIAL AND METHODS}

Patients: A total of 75 patients were enrolled for the clinical trial and all the patients completed the study.

Inclusion criteria: From among 75 patients 40 had problems of colic and griping pain, 15 suffered from indigestion, 9 had flatulence problem and the rest 11 suffered from diarrhea during teeth eruption (Table 2). All infants and children aged between 3 months to 5 years, suffering from abdominal colic with associated spasmodic abdominal pain and griping, bloating of abdomen and excessive crying were included in the study.

Exclusion criteria: Those infants or children who were having severe vomiting and diarrhea, and those suffering with extreme systemic disorder were excluded from the study. Composition of Colicarmin plus drops is given in Table 1.

Procedure: The study was an open, non- randomized and noncomparative, phase III clinical trial, conducted as per the ethical guidelines of Declaration of Helsinki. The study was carried out at Radhika Maternity home, Kalavad road, Nalanda corner, Rajkot.

Pretrial clinical examination: The history was noted by interviewing the parent/guardian. Thorough clinical examination and symptomatic evaluation was carried and noted down in the CRF. Parents/guardians of the patient were advised to administer the drug at a dose given below in table 3 . 
Table 1: Colicarmin Plus drops Composition

\begin{tabular}{|l|l|l|}
\hline Herbs & Use & Quantity/ml \\
\hline Soya (Peucedanum graveolens) & $\begin{array}{l}\text { Relaxes the smooth muscles in the intestine and helps to relieve colicky } \\
\text { abdominal pain }\end{array}$ & $8.00 \mathrm{mg}$ \\
\hline Sukshma Ela (Elettaria cardamomum) & Dysentery and digestive disorders & $6.00 \mathrm{mg}$ \\
\hline Kanta karanj (Ceasalpinia bonducella) & Abdominal disorders & $4.00 \mathrm{mg}$ \\
\hline Sovarchal (Unaqua sodium chloride) & Clears constipation & $4.00 \mathrm{mg}$ \\
\hline Kulianjan (Alpinia galangal) & $\begin{array}{l}\text { Soothe stomach pain, stimulate appetite, curb nausea, motion sickness and } \\
\text { diarrhea }\end{array}$ & $1.00 \mathrm{mg}$ \\
\hline Hing (Ferula foetida) & Intestinal gas and Stomach upset & $2.00 \mathrm{mg}$ \\
\hline Saindhav (Sodii chloridum) & Used in dyspepsia and abdominal disorders & $2.00 \mathrm{mg}$ \\
\hline Nimbu ka Sat (Citrus medica) & Used in abdominal disorders & $2.00 \mathrm{mg}$ \\
\hline Saunf (Anethum foeniculum) & Relieve problems associated with colic & $0.750 \mathrm{mg}$ \\
\hline Nagarmoth (Cyperus scariosus) & Stomach disorders & $0.500 \mathrm{mg}$ \\
\hline $\begin{array}{l}\text { Flavoured Sugar Syrup Base } \\
\text { Colour: Sunset Yellow FCF \& Carmosine }\end{array}$ & $\begin{array}{l}\text { Excipients } \\
\text { Excipients }\end{array}$ & Q.S. \\
\hline
\end{tabular}

Table 2: Classification of Patients according to the observed symptoms for the treatment with Colicarmin Plus Drops

\begin{tabular}{|c|c|}
\hline Indications & Number of Patients \\
\hline Colic and Griping & 40 \\
\hline Indigestion & 15 \\
\hline Flatulence & 9 \\
\hline Diarrhea during teeth eruption & 11 \\
\hline Total & 75 \\
\hline
\end{tabular}

Table 3: Age group of Number of Patients and the given dose

\begin{tabular}{|c|c|c|c|}
\hline Age & Number of Patients & Dose Recommended & Duration \\
\hline Infants below 6 months & 25 & $1-4$ drops & $4-6$ times a day \\
\hline 6 months to 1 year & 25 & $4-5$ drops & $4-6$ times a day \\
\hline 1 year to 3 years & 20 & $5-6$ drops & $4-6$ times a day \\
\hline 3 years to 5 years & 5 & $6-10$ drops & $4-6$ times a day \\
\hline
\end{tabular}

\section{RESULTS}

Table 4: Relief in the abdominal disorders after consuming Colicarmin Plus Drops

\begin{tabular}{|c|c|c|c|c|c|c|c|c|c|}
\hline \multirow[t]{2}{*}{ Indications } & \multirow{2}{*}{$\begin{array}{c}\text { Total } \\
\text { number of } \\
\text { Patients }\end{array}$} & \multicolumn{8}{|c|}{ Number of Patients getting relief at different time intervals after consuming Colicarmin Plus drops } \\
\hline & & $5 \mathrm{~min}$ & $15 \mathrm{~min}$ & $30 \mathrm{~min}$ & $24 \mathrm{~h}$ & $48 \mathrm{~h}$ & $72 \mathrm{~h}$ & $96 \mathrm{~h}$ & $120 \mathrm{~h}$ \\
\hline Colic and griping pain & 40 & 30 & 33 & 37 & 39 & 39 & 40 & 0 & 0 \\
\hline Indigestion & 15 & 4 & 5 & 6 & 10 & 12 & 13 & 0 & 0 \\
\hline Flatulence & 9 & 4 & 6 & 7 & 8 & 0 & 0 & 0 & 0 \\
\hline
\end{tabular}

All patients were followed-up at the end of treatment on day 7 and symptomatic evaluation and clinical examination was done, along with recording of any adverse events

Table 5: Relief in diarrhea during teeth eruption after consuming Colicarmin Plus drops

\begin{tabular}{|c|c|c|c|c|}
\hline Indications & \multirow{2}{*}{ Total number of Patients } & \multicolumn{2}{|c|}{ Number of Patients getting relief } \\
\cline { 3 - 5 } & & $\mathbf{2}$ days & $\mathbf{4}$ days & $\mathbf{7}$ days \\
\cline { 3 - 5 } & 11 & 4 & 7 & 10 \\
\hline
\end{tabular}

During the study more than $50 \%$ symptomatic relief was observed in just 5 minutes in case of Colic and griping pain and for Flatulence relief was observed within 15 minutes. In case of indigestion relief was obtained within 24 hours, while in case of diarrhea during teeth eruption more than $85.00 \%$ relief was obtained within 7 days. The other complains of nausea and vomiting was also reduced by using Colicarmin Plus drops.

\section{DISCUSSION}

Colic usually appears a few weeks after birth and carries on until the baby is about three to four months old. Even though the baby may scream for all he/she is worth, colic is not dangerous or harmful. Experts say colic has no long-term effects and a baby with colic will gain weight and feed normally.
It has been predicted that colic in children could be due to intolerance towards cow's milk, swallowing of air, transient lactase deficiency, tummy trouble, reflux heartburn due to stomach acid and milk flowing back into the windpipe, a growing digestive system with muscles that often spasm, gas, hormones that cause stomach aches or a fussy mood, oversensitivity or over-stimulated by light, noise, etc., a moody baby or a still-developing nervous system ${ }^{6-9}$.

\section{CONCLUSION}

The study carried out on 75 patients with prescribed dosage of Colicarmin Plus drops showed that more than 50\% patients got relief in just 4 days. A significant relief from colic and griping pain, indigestion, flatulence and diarrhea during teeth eruption were observed. Excessive crying due to abdominal pain also 
subsided. Thus Colicarmin plus drops offers many advantages like digestive, carminative and spasmolytic which gives relief from colic and griping pain, indigestion, flatulence, nausea and diarrhea without any side effects. The excellent result of this formulation is due to the blend of herbal ingredients present in it. Each and every ingredient present in this formulation is proved for their effectiveness in various abdominal disorders.

\section{ACKNOWLEDGEMENT}

We are thankful to the Ban Labs (P) Ltd. for supporting the study by supplying samples and other required material.

\section{REFERENCES}

1. Bromberg D. Colic. In: Hoekelman et al., eds. Primary Pediatric Care. 3rd ed. Mosby-Year Book, Inc. 1997:711-712.

2. Savino F, Oggero R, Management of infantile colics. Minerva Pediatric. 1996; 48 (7-8): 313-319.

3. Akman I, Kuscu K, Ozdemir N, et al. Mothers' postpartum psychological adjustment and infantile colic. Arch Dis Child 2006 May; 91(5): 417-419.
4. The Indian Material Medica by Dr. K.M. Nadkarni, Volume I, page no. 936-937.

5. The Indian medicinal plants by C.P. Khare, pp-154-155. (As accessed on 05/04/16)

6. Lucassen PL, Assendelft WJ, Gubbels JW, Van Eijk JT, Douwes AC Infantile colic: Crying time reduction with a whey hydro lysate: A double-blind, randomized, placebocontrolled trial. Pediatrics 2000; 106:1349-1354.

7. Garrison MM, Christakis DA. A systematic review of treatments for infant colic. Pediatrics 2000; 106:184-190.

8. Hill DJ, Hosking CS. Infantile colic and food hypersensitivity. J Pediatric Gastroenterol Nutr 2000; (suppl): 67-76.

9. Hill DJ, Roy N, Heine RG, et al. Effect of a low allergen maternal diet on colic among breast fed infants: a randomized, controlled trial. Pediatrics 2005; 116: 709-715.

\section{Cite this article as:}

Patel Kirtikumar, Gathani Rupali, Mishra Devendra. Clinical evaluation of Colicarmin plus drops on colic, griping pain, indigestion, and flatulence in pediatrics patients. Int. J. Res. Ayurveda Pharm. Jul - Aug 2016;7(4):111-113 http://dx.doi.org/ $10.7897 / 2277-4343.074144$

Disclaimer: IJRAP is solely owned by Moksha Publishing House - A non-profit publishing house, dedicated to publish quality research, while every effort has been taken to verify the accuracy of the content published in our Journal. IJRAP cannot accept any responsibility or liability for the site content and articles published. The views expressed in articles by our contributing authors are not necessarily those of IJRAP editor or editorial board members. 